\title{
Wheel Model: an exposition of competition and
}

\section{cooperation}

\section{Jinwei Lin}

School of physics and materials science, East China Normal University, Shanghai, China

\begin{abstract}
Competition and cooperation are not opposite, but competition and cooperation are closely related. Competition and cooperation are two very important driving forces for the evolution of natural organisms and the development of human civilization. Since the birth of humans, competition and cooperation have always been accompanied by human existence. This paper starts from the introduction of the earth, the universe, human civilization, and the formation of the natural world. This paper expounds that competition and cooperation are the basic principles of nature, and competition and cooperation are not opposite. Then the paper focuses on the relationship between competition and cooperation in human society. Then the wheel model is established. The wheel model is an inductive model. It can be used to vividly describe the relationship between competition and cooperation. In order to better explain the philosophical principle of the wheel model, the basic principle of the wheel model is explained by introducing the circular motion in physics, the collision of the matter principle and the atomic energy level. Then two common examples are given to illustrate the application of the wheel model. Finally, the conclusion and analysis are given.
\end{abstract}

\section{Keywords}

wheel model, competition, cooperation, giving force, getting force, core

\section{Correspondence:}

Jinwei Lin, Department of Electronics and Technology, School of Physics and Materials Science, East China Normal University, Shanghai, China.

Email:JYLINI@I63.com 


\section{Introduction}

The earth is a magical planet. She has nurtured many, colorful creatures. In order to enable organisms to survive and inherit, the earth has bred many, various inorganic environments. Life and non life together constitute the richness of the earth. Green hills and white clouds, green trees and blue skies, sea breeze blowing gently, sunshine shining, birds flying high, horses and rhinos running in the vast grasslands, these are all showing the charm of life on earth all the time. As the most special species on the earth, human beings, from the primitive barbarian tribes to the evolution of modern civilization, has been very prominent.

According to the theory of the Big Bang (Georges Lematre, 1927), the initial universe was disordered. All matter and energy converged on a small point called the singularity, which was a point highly concentrated mass and energy. Because of a huge explosion, all the substances in the early universe will be released. This is a process of entropy increasing. The formation of the universe is interesting and complex. Until now, we know very little about the universe, so little that when we face the vast sky, the heart involuntarily generated reverence. The universe is so beautiful and vast, and as the only earth we know to have life, it is so strange and precious. The question of how the universe works is so far-reaching that even studying how the earth works is a vast book. From the vast universe to our little earth, everything seems to operate irregularly, but it also seems to as if there are certain rules guiding everything. Physicists and astronomers, and so on, have explored more about the laws of the universe, trying to legislate for the sky and the universe. The outstanding representatives of these people, such as Kepler, Galileo, Newton and so on, Einstein, who legislated for space-time, the achievements of these pioneers are admirable. Philosophers and geographers, and so on, explore more about the planet we live on, the laws of the earth, and they legislate for the earth, such as Taylor, Lao Tzu, Darwin, Marx and so on. These scientists or philosophers are great, but what we mean by legislation for the whole universe or for the earth is more about exploring the laws of the universe and the world. The Earth is a very tiny planet in the vast universe, and it is the most special planet we can identify at present. There are many species on earth, and human beings are the most special species. When we face the grassland galloping horse rhino antelope and so on, will be shocked by their display of vitality, when we face the vast universe of bright stars, the universe will be boundless and beautiful and admirable. But we don't know exactly how the universe came into being, we don't know exactly how the earth came into being, we don't know exactly how life came into being, and we don't even know exactly why there was a species of human beings. It is interesting and worth exploring whether there is a law guiding the movement and circulation of all things.

The problem of the universe is too extensive. This paper does not do further research and discussion. We put emphasis on human beings and the earth. Human beings are social 
creatures that are different from other earth creatures. Man invented the "society". One of the biggest differences between human beings and other gregarious creatures is that human beings have social consciousness. With social consciousness, a society is formed slowly, and the society formed will not stop, but will evolve slowly. The history of mankind tells us that society has been improving. In the history of human development, there are many different societies, such as primitive society, slave society, feudal society, capitalism and socialist society and so on. Every society of different nature is maintained by different rules and systems. Social connections exist between people. In addition to human beings, there are links between other organisms. These links include the relationship between individuals and individuals, the relationship between individuals and the whole, and the relationship between the whole and the whole. These associations are varied and interact with each other frequently. The main purpose of this paper is to explore the relationship between competition and cooperation. The relationship between competition and cooperation is not limited to human society.

However, even if only study the relationship between competition and cooperation in human society, it need to cover a wide range of issues. Since human beings have social consciousness, competition and cooperation have never stopped. As far back as the primitive times, gregarious humans had begun competition and cooperation. Competition and cooperation is a long history topic. There are so many things to talk about. Moreover, the form of competition and cooperation is not fixed. For human beings, Competition and cooperation in the primitive era are different from the current competition and cooperation. Competition and cooperation will change with the complexity of the relationship between social system and society. We can say that competition and cooperation are an important part of the social system. There are many factors that can influence the relationship between competition and cooperation, such as the individual ideas, subjective consciousness, the objective environment and conditions of the groups participating in competition and cooperation. According to Darwin's theory of evolution (On the Origin of Species by Means of Natural Selection, Charles Robert Darwin , 1859), species are constantly evolving in competition. Competition is to obtain better resources and living environment conditions, and cooperation is usually a form of alliance in which multiple competitors with unfavorable environmental conditions, for the purpose to form a unified array to compete with one or more advantageous competitors. The relationship and form of competition and cooperation are not single, but very rich and interesting. There are laws to follow concerning competition and cooperation, but thses law is not invariable. They are changing, dynamic, but has the basic rules. In the history of human development, competition and cooperation exist all the time, and often exist at the same time. Competition and cooperation are not antagonistic relations. For example, the opposite of competition is non-competition, but non-competition does not necessarily mean cooperation, the opposite of cooperation is non- 
cooperation, but non-cooperation does not necessarily mean competition. Competition and cooperation will be affected by many factors. At the same time, the forms of competition and cooperation are varied. In order to facilitate the concise description of the basic law of competition and cooperation, we proposed the wheel model. We use wheels that we often see to build models, making the description of the relationship between competition and cooperation more simple and convenient.

\section{Background and related research}

\section{Universal norms of nature}

One of the cores of Darwin's theory of evolution is competition. All things in the world evolve because of competition. At its root, the most basic source of competition is the survival instinct of living beings, that is, to live no matter what they do in the future. "Living" is the most basic requirement for the survival and evolution of organisms. However, "living" is not a simple thing for every creature. According to the prevailing scientific research, the sun was born 4 billion 568 million years ago. Scientists predict the age of the earth by 4 billion 550 million years. Creatures are believed to have been born 3 billion 480 million years ago. Of course, the initial born creatures are very simple. According to a study published in Nature on June 6, 2013 by Ni Xijun(a researcher at the Institute of Vertebrate Paleontology and Paleoanthropology, Chinese Academy of Sciences), and others researchers (Xijun Ni, 2013). It is a series of morphological analyses of a very ancient primate fossil, with surprising results after 10 years of research. It proves that the ape came from about 55 million years ago. Because of the development of measurement technology, these data may not be the most accurate, but it is the most accurate data we can measure at present. Compared with the long history of the universe and the earth, the history of human birth is so short. Biology organisms was born 3.48 billion years ago and evolved more than 34.2 years before humans emerged, those humans called the basic anthropoid ape. According to scientific research, the earth has undergone 5 extinctions of species. (A Hallam, PB Wignall, 1994). We don't know exactly how humans were born, but we can be sure that it's not easy, and the process requires constant competition for survival with different species in different environments. In bad competition between life and death, learning team cooperation will be an excellent evolution.

The history of primitive civilization is too long, and there are too few accurate information about it. We take modern biology as an example to elaborate the relationship between competition and cooperation. Lions and wolves are social animals with strict social hierarchy. Tigers often work alone. Lions often only have one when hunting, while wolves 
often go out in hunting collectively. So if they happen to encounter each other, A lion or a tiger is not afraid of a normal wolf. If they meet a group of wolves, then the lion or tiger has to think about it. Teamwork can unite strength and make the original tiny individuals have strong group strength. Especially those species that do not have too many advantages need the strength of teamwork. Excellent teamwork can greatly improve work giving force, in this regard, the bee and ant performance is very good. But there are competition among team members, such as when it come to the division of food and so on. In the process of biological evolution, competition and cooperation have gradually formed the work rules, and this rule is not unchanged, but constantly changing and evolving according to different environmental conditions and changes.

Competition and cooperation in nature are very common. Almost all creatures can not escape competition and cooperation. Whether animals, plants or microbes are constantly living and evolving in competition and cooperation. We believe that the fundamental reason for continual competition and cooperation among organisms is their survival instinct, that is, "live on". Competition can encourage organisms to evolve towards a more suitable environment for their living environment. Cooperation can make some small living creatures condense strong survivability. All this is for "live on", because only "live on" can "live better". Early life on Earth could not predict the changes in their living environment. All they could do was adapt to the living environment. Only by adapting to the environment better can them obtain more resources for survival. However, resources for survival are usually limited. In the face of limited living resources, competition among organisms is needed. The distribution of living resources can be achieved through competition. Cooperation is born with competition. If every creature had equal access to the same resources, the primitive creatures would not need to cooperate. But species evolve in diversity, not every species has the same ability to survive, so as a way to enhance survival, cooperation is born naturally.

Nowadays, human beings are the most advanced representatives of evolution compared with other species. Now, humans have placed themselves at the top of the natural food chain. But humans are not always on the top of the food chain. In the age of failure to use tools and fire, human beings are also a very weak species. In order to survive, mankind has chosen to cooperate and live together. In order to win in the competition of food acquisition, man invented tools and learned to use tools and fire. In the struggle with wild animals, through numerous dangers and difficulties, human beings continue to survive and evolve under the guidance of competition and cooperation. Cooperation enables human beings to have the fundamental ability to survive. Competition enables human beings to constantly evolve and constantly enhance their viability. 


\section{Competition and cooperation are not opposite}

Competition and cooperation are neither contradictory nor opposite. If there are no other factors interfering, competition is usually a way for competitors to obtain resources. Collaboration is usually a collaborative approach to enhance survival or access to resources. When competing for the same resources, it is not impossible for the competition parties to cooperate. And there will be competition among partners. In the biological world, the fundamental purpose of competition and cooperation is to "live on" and "live better". On the earth, competition and cooperation among different species are very common. For example, in tropical rain forests, many dense plants are growing vigorously. Whether the same species or different species, each different plant is competing for their growth resources, such as sunlight, organic matter, water and so on. Competition exists both inside and outside the population. However, in addition to fierce competition, there are still many cooperation phenomena in the biological world. There is also a cooperative relationship among different plants. There are positive interactions and negative interactions in the interspecific relationships of organisms. The symbiotic relationship in positive interactions is a typical representative of cooperative relations.

Competition and cooperation are not antagonistic. The most direct understanding is that if two or more parties do not compete, they do not necessarily need cooperation. If two or more parties do not cooperate, they do not necessarily need competition. Whether it is competition or cooperation, there is a basic precondition that whether the participants have the related necessary interests. Under the related necessary interests, there are only two kinds of relationshi among two or more parties, one is competition, the other is cooperation. It can also be said that the two or more parties that have the related necessary interests have come together. Or, the two or more parties that do not have the related necessary interests will not come together. The "coming together" here refers to the formation of alliances or hostility. For example, Panthera leo in Africa and polar bear in the ice floes near the Arctic Ocean are both fierce. But obviously, there is no connection between them. Normally, Panthera tigris ssp. altaica, which lives in northeastern Asia, is not particularly associated with Pygoscelis antarctica, which lives in Antarctica. Because of geographical constraints, there is no particularly large interests of competition or cooperation between them. That is to say, it is very difficult for them to have competition and cooperation. Even without geographical constraints, prairie falcons are not competitive or cooperative with Mongolian horses that living on the same Hulunbeir prairie, because they do not have the related necessary interests associated with them. Grassland falcons mainly prey on small animals while Mongolian horses are herbivores. In the interspecies relationship, there are many other relationships besides competition and cooperation. The most common is predation. In jungle rule, predation is the most common state. That is to say, competition and cooperation 
are only necessary when facing the related necessary interests. It is important to note that the interests of cooperation are not necessarily the same interests. The existing interest of competition is "competitive interest". Generally speaking, in a competitive situation, "competitive interest" is "the same interest", that is, the competitor usually competes for the same thing, for example, a tiger and a pack of wolves compete for a deer. In the situation of cooperation, "cooperative interest" is not necessarily "the same interests". For example, wolves cooperate to siege sheep. Their cooperation interests are the same interests, that is the mutton. But there is often no "same interest" among the living things in symbiotic relationship, but they all have "cooperative interest", and their "cooperative interest" is "survival". However, whether the "cooperative interests" are "the same interests", the cooperative interests among the participants must be related, there will be no cooperation without the related interests. For example, clown fishes live in the tentacles of sea anemones. Clown fishes can drive away other fishes that want to eat sea anemone, and sea anemone tentacles have spiny cells that protect clown fishes from other big fishes. Clown fishes themselves also secrete a mucus that wraps around the surface of their bodies, preventing them from being harmed by sea anemone tentacles. Clown fishes and sea anemone have a cooperative interest, that is, "live on". But they don't have the same interests, because one of the purposes the clown fishes chose to cooperate with the sea anemone was to use the sea anemone as their umbrella in situation of emergency. Because the tentacles of sea anemones are poisonous to other fishes and nontoxic to clown fishes. Meanwhile, clown fishes eat the leftovers of sea anemone. The cooperative interest or purpose of clown fishes is to get a protection when they are in danger and get food. The sea anemone chooses and cooperates with clown fishes, and the cooperative interests or purposes is to use clown fishes and acts as bait to attract other fishes close to, and then eat other fishes. At the same time, anemones also need clown fishes to clean up their soil, parasites and other debris. That is to say, the two or more parties with different interests can form cooperation. The interests of cooperation can be the same or different. That is to say, in order to have competition or cooperative relations, the two or more parties must have related necessary interests, which can be "competitive interests" or "cooperative interests". Obviously, if there is no "competitive interest" among the two or more parties, then there is not necessarily "cooperative interest" among them. If there is no "cooperative interest" among the two or more parties, then there is not necessarily a "competitive interest" among them. Therefore, competition and cooperation are not opposites.

\section{Competition and cooperation in human society}


competition and cooperation may be influenced by more factors. Whether in competition or cooperation, the ultimate goal is to gain benefits. In the ancient fishing and hunting Era, the purpose of human competition and cooperation is to get food. In the face of the same strong enemy, different groups of human beings may choose to cooperate to defend against the enemy. Moreover, human beings in the same group belong to the state of cooperative relationship. At this time, human cooperation depends mainly on race consciousness. Each individual in the group works together to defend against foreign enemies, fishing and hunting food. But there is competition within the group, such as the fight for the leader position. There are also competition outside the group, such as the competition among different groups of territories and food. The most obvious manifestation is the era of tribal alliance. In this era, the gregarious human race formed tribes, and people from different tribes often fought for food and territory. At this point, a temporary war alliance, or a permanent alliance through marriage, is a form of cooperation. In order to "live on" and "live better", human beings often change their roles between competition and cooperation. Competition and cooperation are not opposite. Choosing competition or cooperation is just the most reasonable choice for the specific situation. Man was born more than three million years ago, but it was not until about 3,500 BC that basic civilizations emerged. Human civilization has undergone about three million years of arduous journey. In this difficult course, jungle rule dominates all living things. During this period, competition and cooperation among human beings were mainly aimed at acquiring territory and food. And territory and food are the basic guarantee of "live on". During this period, different groups of human beings will compete with each other. Humans compete with other creatures, such as in hunting. Different groups of human beings will cooperate, such as alliance. Humans will cooperate with other creatures, such as the hunting dogs in captivity. Human is a kind of intelligent creature. Competition and cooperation play an important role in surviving more than three million years of bloodshed and evolving. Competition makes humans actively evolve into higher forms, and cooperation is the basis for maintaining constant human competition.

In the age of civilization, competition and cooperation are still important ways of human evolution. In the era of civilization, human beings gradually get rid of the traditional beastliness, with the pursuit of material and living standards, but also the pursuit of beauty and emotion. With the continuous evolution of human civilization, the law of the jungle has played an increasingly low role. As the most advanced form of existence in the development of human civilization, in today's human civilization, hunting and territory is no longer the main purpose of pursuit, or the form of hunting and territory has changed. Modern human beings, in addition to the pursuit of food and housing, but also the pursuit of beauty, emotion, the pursuit of spiritual civilization. The influence of the jungle rule has weakened, but competition and cooperation have not been removed. The relationship among people has 
become more complex and subtle. Competition and cooperation have become more abundant and more complex. The competition and cooperation relationship that will be discussed in this paper is mainly based on modern human beings. People like to use the most representative tools or ideas to divide an era, such as the Stone Age, the Red Bronze Age, the Bronze Age, the Iron Age, the Dark Age, the Age of Enlightenment, the Steam Age, the Electric Age, the Atomic Age, until the Information Age where we are now. The mode of production has become rich, and the forms of cooperative interests have become abundant and varied, so competition and cooperation have become abundant and varied.

The vast majority of mankind today are social. Inevitably, competition and cooperation exist in group society. The reason why human beings gather life is usually there are related necessary interests among them. These related necessary interests, such as a higher standard of living, usually require competitive to obtain. Due to complex social factors, different human beings have different abilities to obtain the means of livelihood. There will inevitably be strong and weak sides. For their own interests, they have chosen cooperation. The interests of cooperation arise. These cooperative interests may be the same or different. As a human being, it is difficult to avoid competition and cooperation unless it is separated from society.

In the modern civilized society of human beings, there are three main support and embody: economy, politics and culture. Human beings living in society are usually inseparable from these three aspects. Competition and cooperation also exist in these three aspects. For example, competition and cooperation among different countries and regions, competition and cooperation among different economies, competition and cooperation among different cultures and so on. It can be said that competition and cooperation run through all aspects of the world we live in. Besides choosing birthplace, human life is spent in the atmosphere of competition and cooperation. Some of us can avoid competition and cooperation, but most of us can not avoid a society full of competition and cooperation, or an atmosphere created by competition and cooperation. There are very few parts of human thought out of society, no longer participate in social survival competition, will not be restricted by the law of social survival. Of course, these are some highly accomplished monks outside the world, not ordinary people can become. As long as we still live in the society, it is very difficult to avoid competition and cooperation. Let's give an example of human growth. When people are born, they come to the world in the form of babies. In general, competition and cooperation are not much related until humans grow up to be schoolchildren, unless the parents have more children at the same time. After the human school, after work began to fight in society, competition and cooperation followed. In modern civilized societies, the interests or purposes of competition and cooperation are not merely meals or territory. The purpose and interests of competition and cooperation become more complex and diverse. In the modern civilized society of humans, it is necessary for 
individuals, teams, groups, societies and countries to have an excellent ability of competition and cooperation.

The key point of this paper is to establish a wheel model to describe the relationship between competition and cooperation visually and concretely. It can make the relationship between competition and cooperation is more clearly and clearly described. It is convenient for people to study and analyze the law of competition and cooperation, so as to better deal with the relationship between competition and cooperation.

\section{Wheel model}

\section{Principle and operation of wheel model}

In order to vividly describe the relationship between competition and cooperation, this paper establishes the wheel model. Wheel model is mainly used to describe the relationship between competition and cooperation, because the principle of its operation graphical, like a running wheel, so we call it "wheel model". This model combines the basic structure of wheel operation, physical characteristics, physical force analysis, to a specific image of the "wheel" to express the relationship between competition and cooperation.

Wheel model is not a criterion deduced by strict physical and mathematical formulas, but an inductive model. The wheel model is a model which is established to describe the relationship between competition and cooperation visually after theoretical analysis of a large number of principles and examples of competition and cooperation. Through the wheel model, the state representation and mechanism analysis of a specific competition and cooperation relationship can be carried out, so that participants can adopt the best coping strategies. Wheel model is an analysis model which is summarized by a large number of examples and experiences of competition and cooperation, and has guiding and advisable effect. That is to say, wheel model is born in reality. But reality is variable. The methods and laws of force analysis in physics generally do not change. But the law of competition and cooperation is changeable. The wheel model is summarized from the laws of the real world, which is used to describe the relationship between competition and cooperation in the real world. Therefore, the wheel model is dynamic and variable. But there are some fundamental theorems in wheel models that will not change. The variability of wheel models helps to apply wheel models to various complex environments.

As shown in Figure 1, the simplest wheel model is displayed. Because the wheel model describes the relationship between competition and cooperation, and to form the relationship between competition and cooperation, there must be more than two participants, so the wheel model has at least two constituent participants. The two participants used "1" 

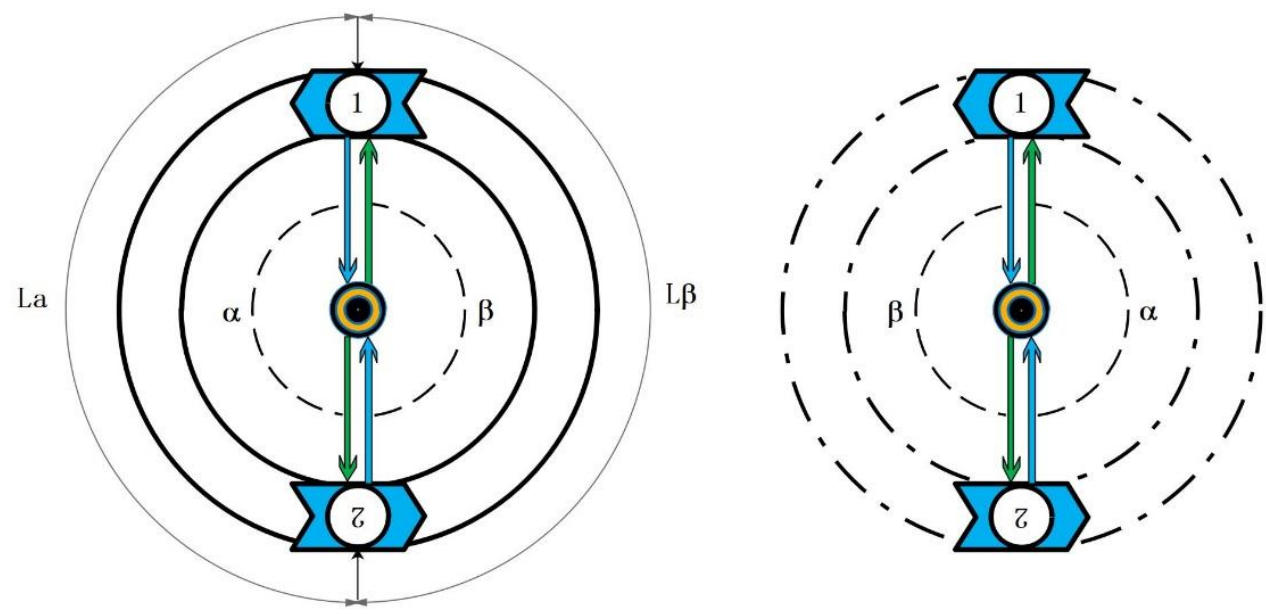

Figure I. The basic composition of the simplest wheel model.

and "2" marks respectively. The six corner arrow of sky blue represents the direction of operation of participants. The whole model of the participants revolves around the core of the model. The orange black circle is the core of the model. The core of the model represents the processing mechanism that drives the operation of the model. It can be competitive interest or cooperative interest, and the interest represented by the core is dynamic and changeable. In wheel models, there are two basic forces, one is repulsive force, the other is attraction force. The repulsive force is represented by green arrows. The repulsive force represents the getting, also known as the getting force. The attraction force is represented by blue arrows. Attraction force represents giving force, also called giving force. Giving force represents the striving or giving force of participants in competition and cooperation. The getting force represents the benefit gained by the participants, that is, the getting. Black circles represent different levels of competition and cooperation, also called as level orbits or orbits. In the wheel model, the orbit does not rotate, and only the participants on the orbit rotate. The rotating means working. The running directions of the participants on the same orbit should be the same. If a participant in one orbit has a different direction of operation from the other participants, the reverse participant is likely to be blocked by collisions with other participants in that orbit. Reverse participants show that the competition and cooperation of the level orbit have betrayed by the reverse participants, which will affect the level orbit.

With a black-orange core as the center, the closer the orbit is to the core, the higher the level of competition and cooperation will be. The core is a symbol of running bearing of the wheel, is the most important part of maintaining wheel operation. When the wheel model works, it needs the core to play its role. The operation of the wheel model means that 
the whole competition and cooperation system can be maintained. Of course, the closer the participants are to the core, the greater the giving force they will have to put into it. This is like racing racing. The more you want to get closer to the curvature center of the orbit, the greater giving force you will have to make. As shown in the right picture of Figure 1, the participants on the same orbit will operate along the same orbit. In the process of running, participants pay continuous giving force and gain continuous harvest. In the wheel model, participants move around the core. On the same orbit, the orbit arc length between two adjacent participants is called the move distance. Taking the core as the core of the circle, the angle corresponding to the move distance is called the moving angle. In the wheel model, each participant has its corresponding move distance and move angle. In the wheel model, the sum of the move angles of all participants on the same orbit is 360 degrees. When dividing the orbit, according to the moving direction, the arc length between the participant 1 and the next participant 2 is called the moving distance of the participant 1 , and the angle corresponding to the moving distance is called the move angle of the participant 1 . As shown in Figure 1, the $\boldsymbol{L} \boldsymbol{\alpha}$ is the move distance of the participant 1, and the $\boldsymbol{\alpha}$ is the corresponding move angle of $\boldsymbol{L} \boldsymbol{\alpha} . \boldsymbol{L} \boldsymbol{\beta}$ is the move distance of the participant 2. The $\boldsymbol{\beta}$ is the corresponding move angle of $\boldsymbol{L} \boldsymbol{\beta}$. The number of orbits of the wheel model is not less than one, and the number of participants is not less than one. If there is only one participant in a certain orbit, then the orbit becomes a solitary orbit. There is only one participant on the solitary orbit, so there is no competition or cooperation within the orbit. That is to say, participants on solitary orbits may only have competition and cooperation between different orbits.

\section{Mechanism explanation of wheel model analogy circular motion}

In order to describe the working mechanism of the wheel model better, we introduce the mechanical mechanism of the circular motion of the physical motion. As shown in Figure 2 , in the physical operation mechanism of the wheel model, the core of the model is the center of the circular motion. The circumference of different radiuses represents different levels of orbits. Use "frepulsion" and green arrow to mark the repulsion force. Use "fattraction" and blue arrow to mark the attraction force. Repulsion force corresponds to getting fore, and attraction force corresponds to gving force. Here, 4 orbits are selected for analysis, named A, B, C, D respectively, according to the distance from the core, from near to far. Then take 2 points on A, B, C and D as participants' points to analyze respectively. The four points on the left side of the core in Figure 2 are level to the four points on the right. The eight points are centrally symmetric base on the core. These four level points are expressed in black, red, yellow and purple. 


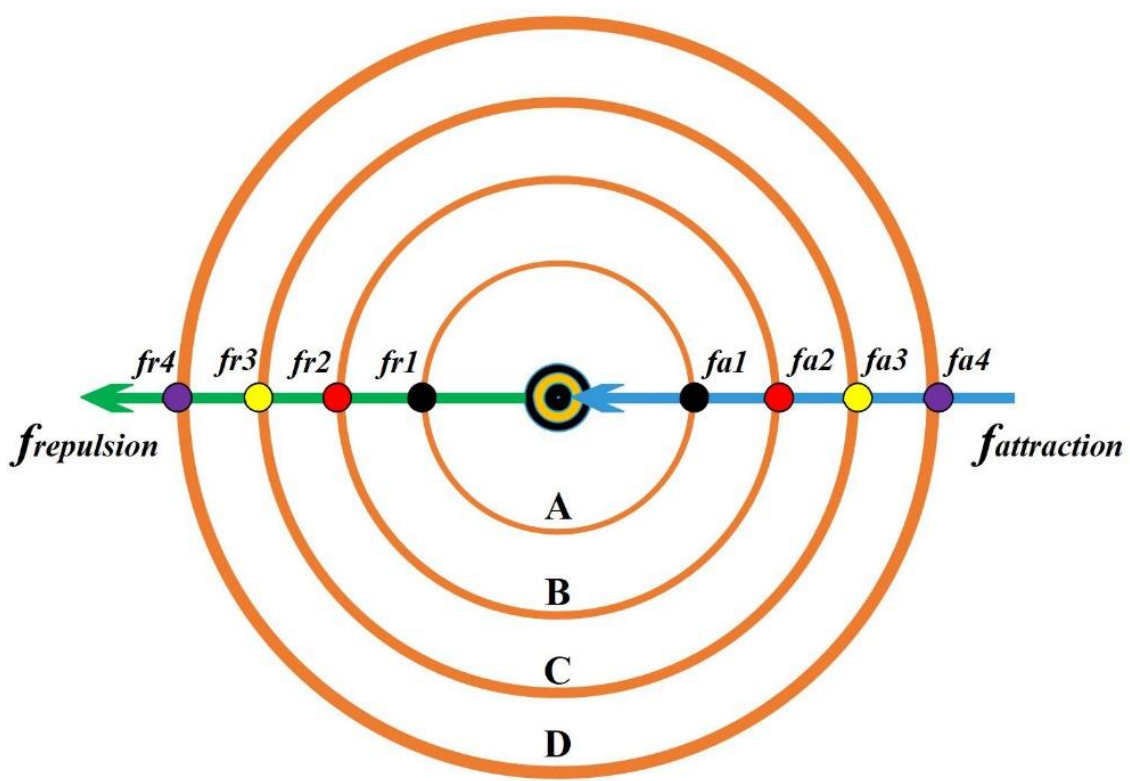

Figure 2. The force explanation of wheel model.

According to the characteristics of circular motion in physics, a object needs a centripetal force when it moves around the center of a circle. The formula for centripetal force is:

$$
F_{\text {centripetal }}=m v^{2} / r=m \omega^{2} r
$$

For stable circular motion, there must be a centrifugal force keep balance with the centripetal force above. And the centrifugal force is:

$$
F_{\text {centrifugal }}=-F_{\text {centripetal }}
$$

The $\boldsymbol{m}$ of the upper form is the mass of the particle, and $\boldsymbol{R}$ is the radius from the particle to the center. $\boldsymbol{V}$ is the linear velocity of a particle moving around a center, $\boldsymbol{\omega}$ is the angular velocity of a particle moving around the center. We have introduced the circular motion of physical motion, not to discuss the force rules of circular motion. But to better describe the operating mechanism of the wheel model. The centrifugal force "Fcentrifugal" of the circular motion corresponds to the getting force of the wheel model. The centripetal force "Fcentripetal" of the circular motion corresponds to the giving force of the wheel model. The mechanism of the force of the wheel model is similar to that of the circular motion. As shown in Figure 2, the core of the wheel model is analogous to the center of the circle motion. The core of the wheel model represents the distribution and processing mechanism 
of "competitive interest" and "cooperative interest" in the relationship between competition and cooperation. As shown in Figure 2, corresponding to the circular motion, the wheel model has the following force relations under balanced conditions:

$$
f a i=-f r i(i=1,2,3,4 \ldots)
$$

Their size has the following relations:

\section{$f a 1>f a 2>f a 3>f a 4 \ldots \quad f r 1>f r 2>f r 3>f r 4 \ldots$}

The closer the orbit is to the core, the greater the giving force required to maintain its operation and the greater the corresponding getting force. The wheel model is a fair and reasonable competition and cooperation mechanism. To achieve greater gains, we must make an equal giving force, that is, the level giving force. The wheel model encourages participants to move ahead to a more higher level orbit. The closer to the core of the orbit, the shorter the distance required to operate a circle. And the more higher level orbit participants on, the greater the gains they get from a circle of operation, that is, the greater the benefits. But it's not easy to run near the core. The closer you are to the core, the greater the giving force you will have to give. The greater the ability to give the giving force, the greater the ability of the participants to have. However, not every participant has great ability at the beginning, so participants in the competition need to constantly enhance their ability to improve their self-competitiveness. All participants have a common goal: "close to the core". The core of the wheel model is not real, so participants can only infinitely close to the core, not reach the core. Wheel model is dynamic, the number of participants in the model will increase or decrease, and the level orbit will increase or decrease. The same is true of the relationship between competition and cooperation. The environment of competition and cooperation will not remain unchanged. Participants need to pay close attention to the changes of environment and conditions in competition and cooperation in real time. When studying the static wheel model, it is necessary to select a wheel model at a certain time for analysis. The wheel model under normal condition will not stop. Once the wheel model stops running, the whole competition and cooperation will be over. We call the orbit close to the core of the wheel model a high-level orbit, the higher the level of the orbit, the closer to the core. The wheel model is based on fairness, and the higher the orbit, the greater the giving force the participants will have to pay, but the greater the harvest they will get. The lower the orbit, the less giving force the participants will have to pay, but the less rewarding they will be. In the wheel model, a participant on the orbit runs for one week, indicating that the competing and cooperative task of the participant completes a running phase, which corresponds to a cycle of motion of the circle. At the same moving speed, the 

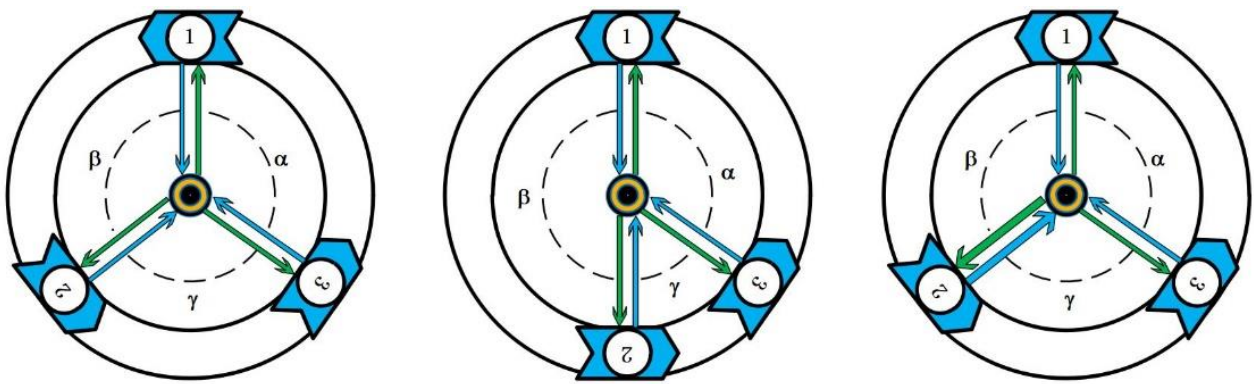

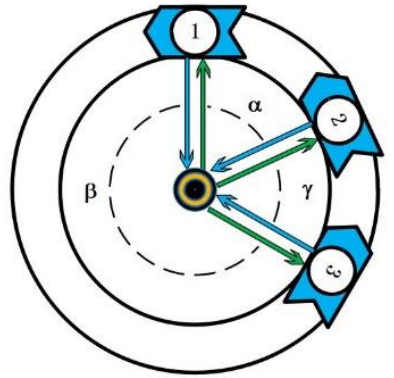

d. Overtake successfully

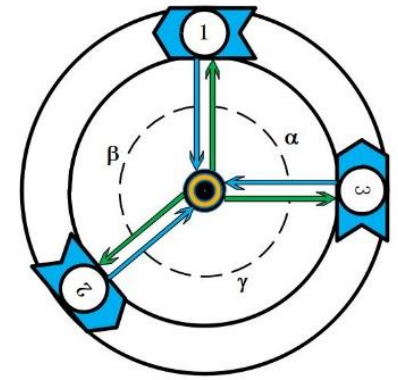

e. Overtake unsuccessfully

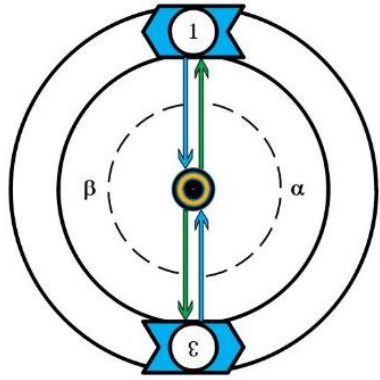

f. Participant 2 out of orbit

Figure 3. Competition and cooperation among participants on the same orbit.

higher the level of the orbit, the shorter the moving distance the participants have to walk during one running phase of the participants on the wheel model. In the wheel model, the moving distance of the participant in a running phase represents the amount of task that the participant has to complete in this phase. The longer the moving distance, the greater the task of the participants. But considering the magnitude of giving force, participants on highlevel orbits do small tasks with great giving force, while participants on low-level orbits do large tasks with little giving force.

The wheel model is dynamic and can be used to reflect the relationship between competition and cooperation in real time. The detailed operation principle of the wheel model will be discussed in detail, with the mechanism of circular motion as the basic.

There are two kinds of running state on the same orbit in the wheel model, one is balance state, the other is non-balance state. The balance state can be divided into complete balance state and incomplete balance state. Whether a certain level orbit is in balance or non-balance state in the wheel model needs to be judged according to the distance or angle between the participants and the force exerted by the participants on the core and the force exerted by the core on the participants. As long as the sum of all the participants' giving forces equals to the sum of all the participants' getting forces, the orbit is in the balance state. 

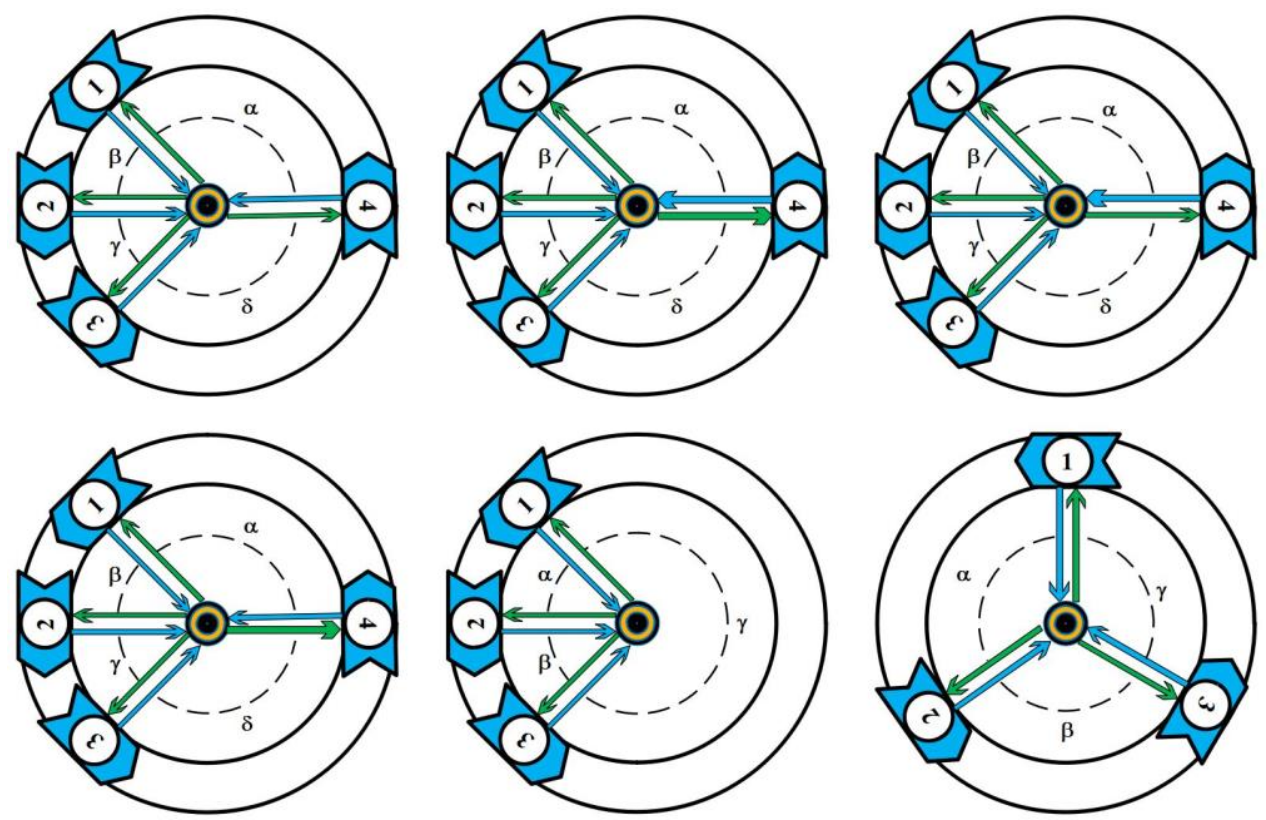

d. Increase the getting force

e. Participants out of the orbit

f. Rebalance

Figure 4. Wheel model, the analysis of the input force and the output force of the core.

Complete balance state: In the wheel model, if the moving angles of each participant on a certain orbit are the same and the intput forces and output forces on the core by each participant are equal, the orbit is in the complete balance. When an orbit is in complete balance state, the orbit is in the best state of cooperation. As shown in Figure. 3. Each participant on the same orbit has the same giving force and getting force, and each participant has the same move angle. At this time, participants on the same orbit have no competitive relationship and are fully cooperative. But competitors on different orbits may still have competition. In the wheel model, participants on the same orbit compete through overtakeing and collision. In reality, it is difficult to achieve a completely balance state of competition and cooperation, which requires that all participants on the same orbit must cooperate equally, assume the same responsibilities and obligations in cooperation, and face the competition of participants on other level orbits together. And there is no competition among partners. This is also a state of "it doesn't differentiate between you and me".

Incomplete balance state: In the wheel model, if the moving angles of each participant on a certain orbit are not all the same, or if more than one participant exerts input force and output force on the core is different from other participants, but the total amount of input force and output force on the core by all participants are the same, the orbit is in the incomplete balance. If the moving angles of the participants in the same orbit are different, 
incomplete balance will occur. The Diagram a and b in Figure 4 show a state of incomplete balance. The move angles among participants 1, participants 2 and participants 3 are different, the corresponding move distances are also different. But on the same orbit, the total amount of input force and output force on the core is the same for all participants. If a certain level of orbit is in this state, and no participants derail, then the orbit can continue to maintain stable operation. At this point, the model core is taken as the central axis of the wheel, and through the force analysis, participants 1,2, 3 gather together to form a cooperation hugging phenomenon. The giving forces among participants 1, 2, 3 is transformed into the getting force of participant 4 through the core competition and cooperation mechanism. The giving force of participant 4 is transformed into the overall getting force of participants 1, 2, 3 through the core competition and cooperation mechanism. Incomplete balance is not the ideal state of cooperation, because some participants on the orbit are likely to gather together to be a giant participants or threre will be some participants clumped phenomenons. But in reality, the imcomplete balance is the most common. Since total amounts of input force and output force on the core by all participants on the same orbit are the same, the operation in this state is fair. As shown in Diagram a and b of Figure 4, are incomplete balance.

Nonbalance state: In the wheel model, if total amount of input force and output force on the core by all participants are not the same, the orbit is in the nonbalance state. In the nonbalance state, the orbit can maintain the operation, but this operation is unfair, it is easy to lead to derailment of participants. As shown in Figure 4, the orbits in the Diagram c and the Diagram d are all unbalanced. Although the nonbalance state is unstable, it is also a common state of competition and cooperation in reality. However, from the perspective of long-term stable relationship of competition and cooperation, nonbalance state should be avoided as far as possible. In the wheel model, nonbalance state will likely occur when one or more participants on a certain orbit have unequal giving forces and getting forces, if without the intervention of the participants on other orbits. What is said here is likely, not necessarily. For example, on a certain orbit, only participant A and participant B show unequal giving force and getting force. But the giving force of participant $\mathrm{A}$ is just equal to the getting force of participant $\mathrm{B}$, and the getting force of participant $\mathrm{A}$ is equal to the getting force of participant B. Thus, although local participants have different giving forces and getting forces on the core, the sum of all participants' giving forces to the core is equal to the sum of the getting forces, so the orbit is still in balance.

In the wheel model, the process in which the participants leave the orbit and jump to other orbits is called the energy level transition of the participants. If on the same orbit, a participant is not satisfied with the competition and cooperation on current orbit, want to jump to a higher orbit. According to that the centripetal force is level to giving force in the wheel model, the participant needs to speed up to make the movement faster. That is to say, 
the participant needs to make greater giving force, which means greater giving force. In the wheel model, if the participants on a certain orbit jump successfully or leave the current orbit, then the role tasks of the core on the original orbit will be assigned by the remaining participants on this original orbit. Because in the wheel model, the orbit is not rotating, and only the participants on the orbit rotate. So the different locations on the orbit represent the different task points or action points of the corresponding participants, when the wheel model runs for a circle. Therefore, if a participant in an orbit is out of orbit, the operation of the orbit will be the responsibility of the remaining participants in that orbit. At this point, all participants on the orbit will gain more getting force from the core. Correspondingly, if the orbit at this time is to continue to operate steadily, then the participants in the orbit must increase the sum of their giving forces. Ultimately, the best operation state of the orbit will be that the original tasks are divided to the remaining participants to do. That is, divide the move angle of the orbit equally. As shown in Diagram e and f of Figure 4.

A participant on an orbit is out of the current orbit with three results: 1. the participant abandons or is expelled from the current competition and cooperation model; 2 . the participant jumps to a higher orbit; 3 . the participant jumps to a lower orbit. Please refer to the Section 3.3 for detailed analysis.

\section{Mechanism explanation of analogy of atomic energy level model}

When we analyze Bohr Atomic Models (Ni.Henrik David Bohr,1913), we are surprised to find that some basic ideas of it is very similar to the wheel model, when cuts the wheel model along a point from the core to the outermost orbit of the model and spreades it out, but there are some differences. Here, analogous to Bohr Atomic Models, we will explain in detail the principle of level transition of the wheel model by using the energy level structure of the spreaded wheel model.

In the wheel model, the core represents the mechanism or relationship between competition and cooperation, but the core does not exist in reality. The highest level orbit is the closest orbit to the core, called as the "ll" orbit. Starting from the core, from inside to outside, the the level of orbits decrease in turn. As shown in Figure. 4, in the wheel model, the distribution of level orbits is not continuous. Participants moving on their respective orbits. The moving distance between two adjacent participants on the same orbit is still determined according to the direction of progress. For example, in Figure 4, the moving distance of participant 1 is $\boldsymbol{L} \boldsymbol{\alpha}$, and the moving distance of participant 2 is $\boldsymbol{L} \boldsymbol{\beta}$. The $\boldsymbol{l 0}$ level represents the core. The core is that the participants can not reach to. In the wheel model, the participant's ability, i.e. initiative ability, is represented by the participant's giving force fgive, which represents the role that the participant can play in the competition and 

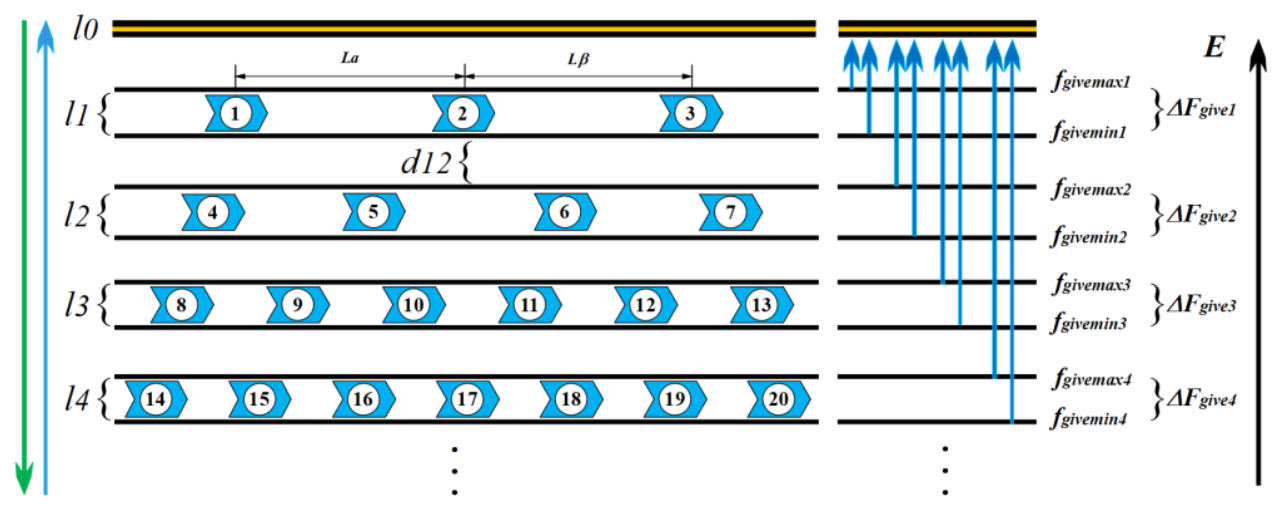

Figure 5. Energy level orbit model of wheel model.

cooperation system. In the wheel model, the spatial energy distribution is continuous, but the distribution of level orbits is not continuous. As shown in Figure 4, $\boldsymbol{E}$ represents the distribution of energy throughout the space from infinity distance to the core, and the energy increases in succession. Because the wheel model is dynamic, it needs to be analyzed according to the actual situation. So what we can be sure of is that the energy at infinity in space is zero, but we can't be sure of the energy nearest the core. This needs to be determined by combining the actual situation. In the wheel model, although the energy is continuously distributed, the position of the level orbits is not continuously distributed. There is energy gap among the level orbits, and the energy gap represents the difficulty of the transition among the different orbits. The energy gap between the $\boldsymbol{l} \boldsymbol{1}$ orbit and the $\boldsymbol{l} \boldsymbol{2}$ orbit in Figure 4 is $\mathbf{D 1 2}$. The larger the $\mathbf{d 1 2}$, the greater the ability of participants to transit from the lower orbit $\boldsymbol{l} \boldsymbol{2}$ to the higher orbit $\boldsymbol{l} \boldsymbol{1}$, that is, the greater the $\boldsymbol{f}$ give. It should be noted here that Figure 4 sets the energy gaps for each orbit roughly the same for ease of illustration, which is not necessarily the situation. The participant's fgive is directed to the core, represented by a blue arrow, and the $f_{g e t}$ returned by the core is directed to the participant, represented by a green arrow. The energy of the participants is measured by fgives. The distribution of orbits is not continuous, which results in different energy gaps in different orbits. That is to say, the fgives of the participants on different orbits needs to meet certain distribution intervals. In the wheel model, each level orbit has a maximum fgive, called fgivemax, and a minimum fgive, called fivemin. For example, the maximum and minimum forces on orbit $\boldsymbol{l} \boldsymbol{2}$ in Figure 4 are fgivemax 2 and fgivemin 2 respectively. The difference between fgivemax and fgivemin in the same orbit is called the interval of the orbital giving force and is called the $\boldsymbol{\Delta F}$ Five. That is:

$$
\Delta \text { Fgive }=\text { fgivemaxi }- \text { fgivemini } \quad(i=1,2,3, \ldots)
$$


move steadily on that orbit. In other words, if a participant's fgivemax is fgivemax_p, and he wants to jump to the $\boldsymbol{l i}$ orbit, he must satisfy the following relationship:

\section{fgivemini $\leq$ fgivemax $p \leq$ fgivemax}

The competition relationship in the wheel model is rigorous and cooperation is diverse. There will be competition and cooperation with participants on the same orbit. Competition and cooperation will also take place among participants from different orbits. The level of participants can be determined by their own ability of giving foorce. To jump to a higher level orbit, the participants must increase their giving forces, that is, to work harder and enhance their own capabilities. If the participants on an orbit become negative and their giving forces diminishes, they are likely to jump to lower level orbits. As for the participant's specific ability to jump to that orbit, it needs to be determined according to the increase or decrease of the participant's giving forces. Some participants may jump to the lowest level orbit at once, and some participants may jump to the highest level orbit at once. The wheel model tells us that if the participants want to gain more advantages in competition and cooperation, the participants must enhance their abilities, that is, enhance the giving forces.

Next, we will combine the energy level orbit model of the wheel model with Figure 5 to illustrate the process of jumping off the current orbit. When a participant wants to get out of his current orbit, the participant must increase his giving force. According to the wheel model, the greater the giving forces of the participants, the faster they moving and the greater their energy. Since there are at least one participant on the same orbit, the accelerated participant must determine if there are other participants ahead. If there are no other participants in front, the accelerated participants can accelerate without obstacles. Participants on the solitary orbit can jump out of the current orbit by accelerating or decreasing continuously, when the participant's fgive and $\boldsymbol{f g e t}$ are not in the $\boldsymbol{\Delta F}$ give interval. Next we will discuss the situation of there are other participants in front.

Because of the acceleration, if the speed of the participants ahead remains unchanged, then the accelerated participants will encounter other participants. If the accelerating participant has the same competitive advantage as the one he will encounter, the accelerating participant will be in danger. If the accelerating participant ahead has no competitive advantage with the accelerating participant, or if the accelerating participant ahead is not interested in blocking the accelerating participant, the accelerating participant can continue to increase his speed directly. If the participants in front want to stop the participants from speeding up, then it will be a competition of strength. If the accelerating participant is stronger than the one ahead, the accelerating participant will succeed in overtaking the ahead participant, as shown in Figure 3. After successfully overtaked, the 


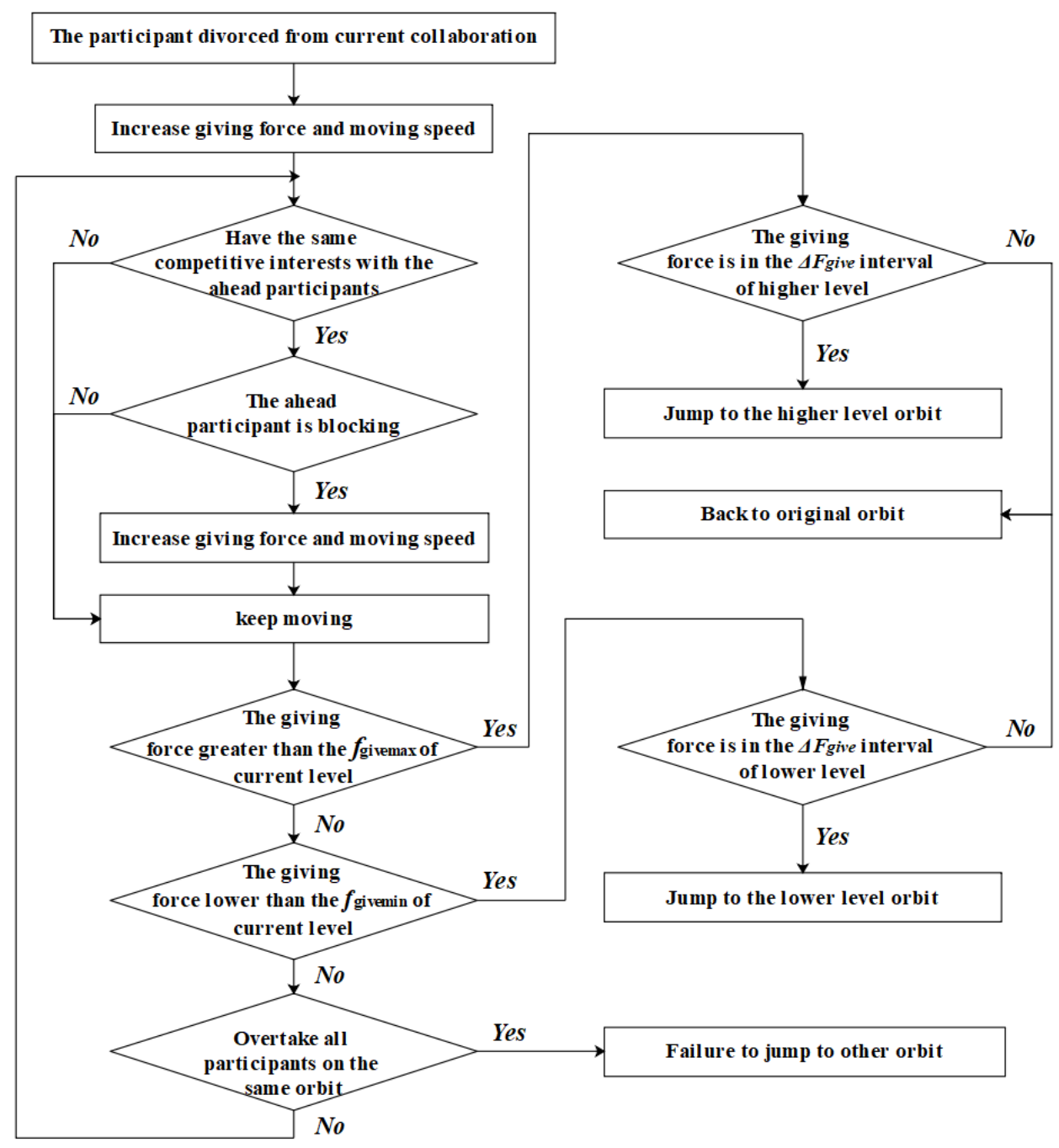

Figure 6. The overtaking process of participant in the same energy level orbit of wheel model.

accelerated participant will decelerate and has some energy expenditure during the overtaking. This is similar to the collision process in physics. The energy transfer of two objects will occur during the collision process of the two objects. If the accelerating participant is less powerful than the one ahead, the accelerating participant will not be able to overtake the one ahead. If the overtaking is unsuccessful, it is likely to cause the ahead participant to speed up, increase the distance between the accelerating participant and ahead participant, and make it more difficult for the next overtaking. As shown in the Diagram e of Figure 3. If the accelerating participant also wants to try to overtake the ahead participant, then the accelerating participant must continue to increase the speed.

If a participant wants to get off orbit, his most effective way is to constantly change 
his moving speed. In the wheel model, the moving speed represents the energy of itself, that is, ability. Accelerated participant may or may not be blocked by the ahead participants. This should be determined according to the actual situation. But it is certain that the moving speed of the accelerated participant will be affected once he is blocked by the participants ahead. There are three major relationships among participants on the same orbit: competitive relationship, indifferent relationship, and cooperative relationship. Competitive relationship are also called blocking relationship, where the ahead participants will slow down the accelerating participant. If the relationship is irrelevant relationship, and the ahead participants of it don't do anything to influence the acceleration process of the accelerating participant. Cooperative relationship is a helping relationship. If the relationship is a cooperative relationship, the ahead participants will help the accelerating participant to accelerate.

In the process of changing the moving speed of the participant, if the participant moves faster than the orbit fgivemax, or if the participant moves slower than the orbit fgivemin, the participant will be get out of orbit. However, if the participant's fgive does not meet the $\Delta F$ give interval of the effort he wants to enter, the participant will change the speed and return to the original orbit. Another situation is that after derailment, the participant abandon the competition and cooperation system, or are made clear by the system, and no longer enter any of the orbits in the wheel model. In general, the most effective and direct way for participants to get off orbit is to change their own speed. That is to change the energy of the participants themselves.

\section{Competition and cooperation among level orbits of wheel model}

In the wheel model, there are two forms of competition, one is the competition among participants on the same level orbit, the other is the competition among participants on different level orbits. In the wheel model, there are two forms of cooperation, one is cooperation among participants on the same level orbit, the other is cooperation among participants on different level orbits.

Participants on the same orbit belong to the same level, so competition of the participants on the same orbit competes for which participant can achieve greater getting force and which participant can jump to higher levels faster. When the participants in an orbit are in complete balance state, all the participants on the orbit are cooperative. As shown in Figure. 7. When a participant in the same orbit accelerates closer to the participant in front of it, as shown in Diagram b of Figure 7, there are three situations. In the first situation, there is no competition and cooperation between the two, then the accelerated participant can passed smoothly. In the second situation, there is a competitive relationship 

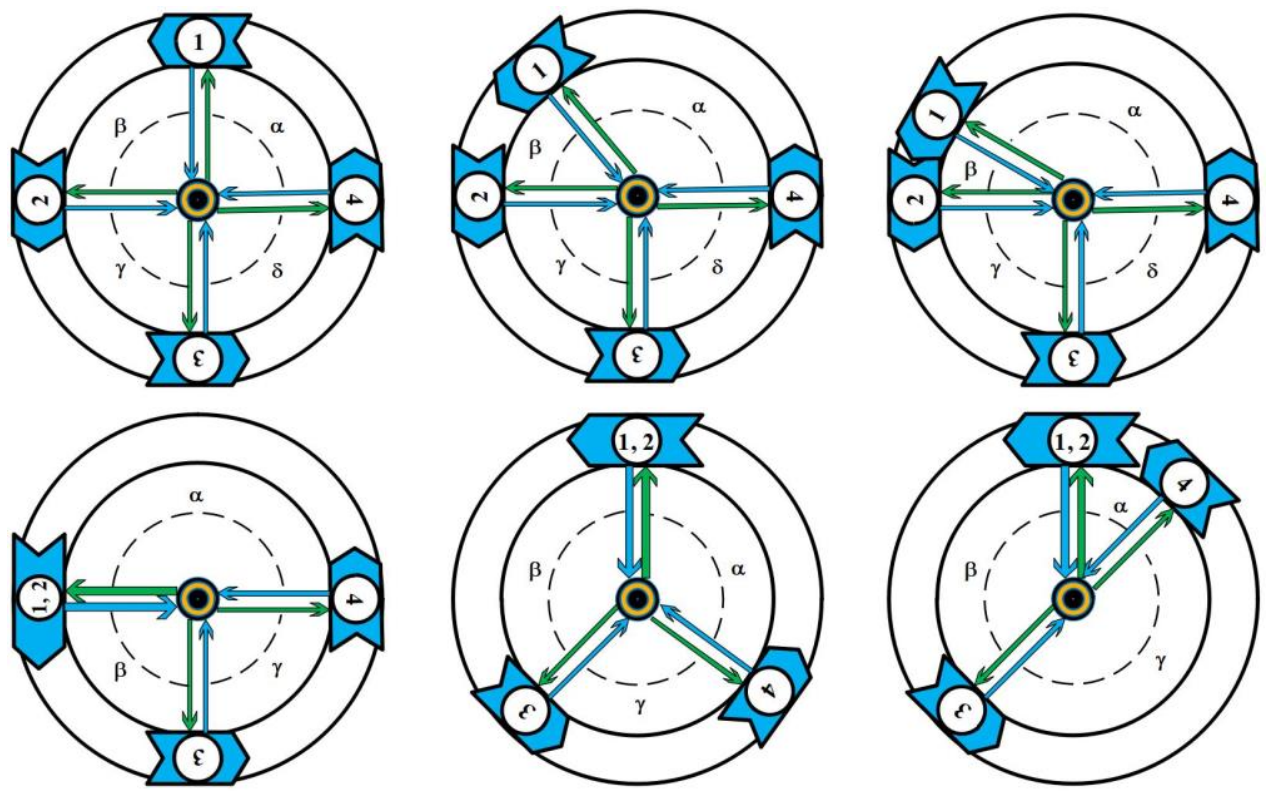

a. Participant I combined with the 2

b. Rebalance

c. Participant 4 closing to the $(I, 2)$

Figure 7. Competition and cooperation on the same orbit of wheel model.

between the two, and the accelerating participant are blocked by the ahead participant. In the third situation, there is a cooperative relationship between the two, and the accelerated participant is helped by the participant in the front. Because the orbit is fixed in the wheel model, different parts of the orbit represent different stages of business in one phase of the system of competition and cooperation. Therefore, in the normal operation of the wheel model, the smaller the angle between the two participants, the closer the two participants are. In the competition and cooperation system, two or more participants most closely related are most likely to become the object of competition or cooperation. As shown in Figure 7, when two participants come into contact, it is likely that there will be a phenomenon of competition overtaking or cooperation hugging. Competition overtaking is a competition phenomenon among participants on the same orbit. It has been described in previous chapters. Cooperation hugging is a cooperation phenomenon among some locally and closely related participants on the same orbit. Cooperation hugging is a cooperation way to face external competition. Participants who choose to cooperation hugging will form a new whole and then continue to join in orbit. There is no competition among the cooperation hugging participants. The cooperation hugging participants will face the competition outside together. Cooperation hugging is the highest form of cooperation among participants on the same orbit. As shown in the diagram d of Figure 7, participant 1 and participant 2 work together to form a new participant, called a participant $(1,2)$. The 
names in the bracket of name of the group participant are the names of individual participants. After cooperation hugging, the group participant can continue to cooperate with other group participants or individual participants without clutching. For example, participant $(1,2)$ and participant $(3,4)$ club together, forming a new group participant wil be the participant $((1,2),(3,4))$, and so on. The new group participant will continue to operate in the original orbit. At this point, the giving force and the getting force of the group participant will increase equally, and equals to the total giving forces of all the members of the group participant, or the sum of the getting forces. Although the participant's total giving force and getting force did not change before and after the cooperation hugging. But as a new individual participant, the group participant's giving force increases, the group participant will move faster, work more efficiently, speed up, and have a better chance to jump to a higher level of orbit. This is an advantage of cooperation hugging. After the cooperation hugging, the group participant will continue to operate on the orbit and gradually form a stable competitive and cooperative relationship with the remaining participants. The orbit will form a new complete balance. Another advantage of the group participant after the cooperation hugging is that their ability to withstand the collision of other participants is enhanced. On the same orbit, their competitiveness is enhanced. As shown in the Diagram $\mathrm{f}$ in Figure 7 , when participant $(1,2)$ and participant $(4)$ are about to collide overtake each other, group participants $(1,2)$ will be more advantageous than participant 1 or participants 2 without cooperation hugging.

The level orbit of wheel models is usually multiple. The higher the level orbit, the higher the giving force of the participants. In other words, during a running circle of the wheel model, at the same speed, that is, under the same effort, the higher the level orbit the participants on, the smaller the moving distance. The smaller the moving distance, the higher the giving force to need, but the less energy consumed and the higher efficiency. In order to understand vividly, we can consider the multi-orbit wheel model as race orbits composed of many circular orbits. The participants in the orbits of the wheel model are racing cars or athletes. At the same time, record the circle numbers that the cars or athletes passed. Obviously, the closer to the core the race orbit is, the better. In the wheel model, the higher level the orbit is, the greater the getting force. So the participants in the whole competition and cooperation system want to jump to a higher level orbit. Therefore, competition exists among participants on different orbits. With competition, cooperation is naturally exist. As shown in Figure 8, the cooperations among participants on different orbits of the wheel model are shown. On the $\boldsymbol{l} \boldsymbol{1}$ orbit, participant 1, 2, 3 are closely related, and if they choose to cooperation hugging, it will pose a threat to participant 4 . At this time, the getting forces of participant 4 increased, but the giving force of participant 4 was still the same size. Participant 4 is likely to be pushed to a lower orbit level, $\boldsymbol{l} 2$ orbit, by the greater getting force exerted by the core on Participant 4. 

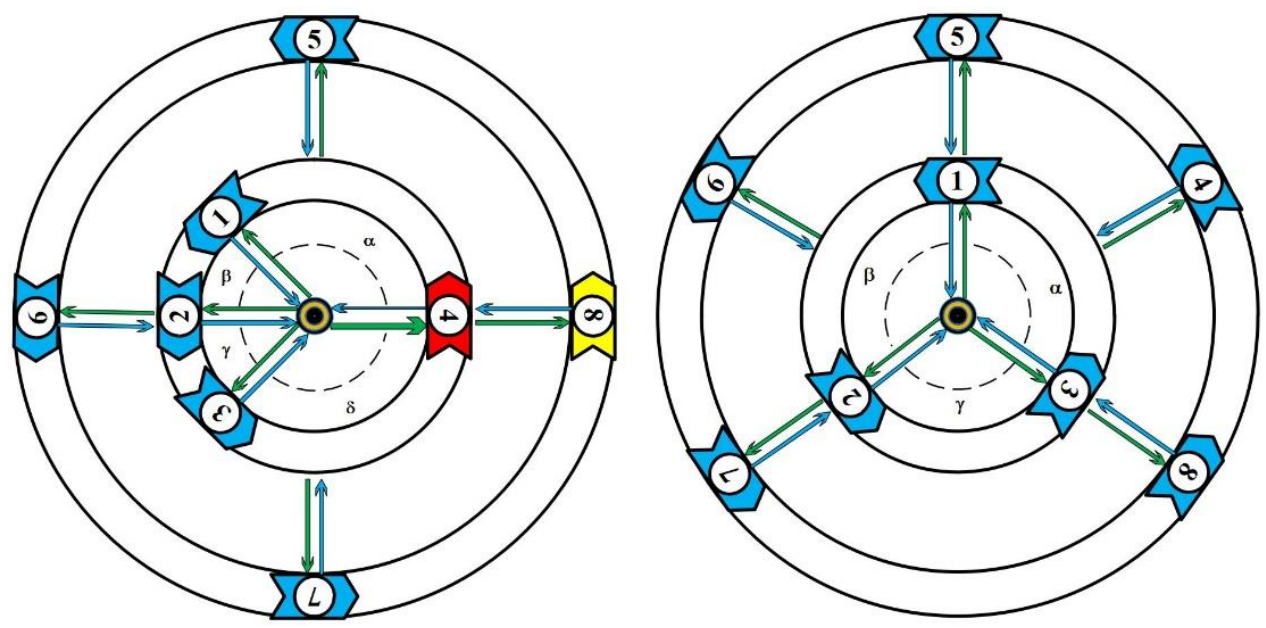

Figure 8. Competition and cooperation in different level orbits of wheel models.

We use red to represent participants 4 . At this point, participant 4 needs to increase its giving force and speed up its moving so that it can stay on orbit $\boldsymbol{l 1}$. In addition, participants can use the help of participants on the external orbit. As shown in Figure 8, in the outward direction of the core radial direction, the position corresponding to participant 4 in the $\boldsymbol{l} 2$ orbit is exactly participant 8 . The cooperation relationship between participant 8 and participants 4 was formed. After forming a cooperation relationship among orbits, participants on different orbits can directly interact with each other in terms of giving forces and getting forces. That is to say, the participants on different orbits cooperation can transmit the giving forces and the getting force. As shown on the left diagram of Figure 8, although participant 4 gains more, participant 4 can transmit the extra getting force directly to participant 8 to reduce core repulsion force and thus continue to operate steadily on orbit I1. At the same time, participant 8 also exerts direct effort on participant 4 to enhance the attraction force of the core to participant 4 . As a result, participant 4 continues to operate steadily on the $\boldsymbol{l l}$ orbit.

In the wheel model, only the $\mathbf{l} \mathbf{1}$ orbit can directly interact with the core. The $\boldsymbol{l i}$ level orbit, when $\boldsymbol{i}>\mathbf{1}$, finally interactes with the core through the front $\boldsymbol{i}-\mathbf{1}$ orbit layers. Because of the interval among the intermediate orbital layers, the orbit of the $\boldsymbol{i}(\boldsymbol{i}>\mathbf{1})$ layer can not directly interact with the real model core. For the $\boldsymbol{i}(\boldsymbol{i}>\mathbf{1})$ level orbit, the inner front $\boldsymbol{i}-\boldsymbol{1}$ layer orbit constitutes an equivalent core. That is to say, for the orbit of the $\boldsymbol{i}(\boldsymbol{i}>\boldsymbol{1})$ orbit layer, the orbit of the front $\boldsymbol{i}-\mathbf{1}$ layer in the inner layer is the equivalent core of the orbit. Therefore, a wheel model with $\boldsymbol{m}$ level orbits has $\boldsymbol{m}-\boldsymbol{1}$ equivalent cores. However, the equivalent core is not the real core after all. It is a method to treat the complex mechanism as a whole by considering the whole of the front $\boldsymbol{i}-\mathbf{1}$ orbits in the inner orbit layer as an equivalent core of the $\boldsymbol{i}(\boldsymbol{i}>\mathbf{1})$ orbit. For the participants in the $\boldsymbol{l 1}$ orbit, they don't have to worry about is there 
any participant jump out of the core to the $\mathbf{l 1}$. For the participants in the $\boldsymbol{i}(\boldsymbol{i}>\mathbf{1})$ orbit layer, need to consider whether there will be participants in the $\boldsymbol{j}(\boldsymbol{i}>\boldsymbol{j})$ orbit layer jumping up to their orbit, they also have to consider whether the participants who in the equivalent core will jump to their orbit. Therefore, the wheel model encourages participants to become members of the $\boldsymbol{l 1}$ orbit. But becoming a participant on the $\boldsymbol{l l}$ orbit is also risky. Because the core is the processing mechanism of competition and cooperation. However, the mechanism for dealing with competition and cooperation are variable, and once it changes, the participants on the $\boldsymbol{l} \boldsymbol{1}$ orbit are be affected firstly. Of course, this effect is not necessarily bad, it can be good. That is to say, being a participant on the $\boldsymbol{l 1}$ orbit is risky. So becoming a participant in the $\mathbf{l} \mathbf{1}$ orbit requires courage and ability. As the level orbits continue to extend outward, the direct forces acting on the real core of the participants who in the orbit are gradually weakened. But the participants will be more relatively safe. Because if the real core of the model has changed, it can be processed and alleviated through the multilayer internal orbital layers, and when it reaches the outer orbit, it is already affected and processed by many factors in the multi-layer orbit.

So the wheel model tells participants that if they want to get more direct harvest from the real core, they have to constantly improve their energy, that is, to constantly increase their maximum giving force, that is, to constantly enhance the attraction force by the real core to their own. This is the meaning of competition. In order to move faster, more core getting force, more core attraction force, constantly improve their own level. Of course, although the wheel model encourages participants to jump to higher level orbits, there are still a lot of participants who are less temperamental and enjoy a simple and leisurely life. For these participants, it is also suitable to run on the lower outer orbit of the wheel model.

Participants on the lower orbit, if they want to gain more core getting force, can not only enhance their own maximum giving force, thus jumping to a higher level orbit, but also through direct tie to achieve. A direct tie is a direct relationship between two participants in an adjacent level orbits if they are in the same radial direction starting from the core and they form a cooperative relationship among the orbits. For example, in the left picture of Figure 8, the participant 6 and participant 2, participants and participant 8 . In the right picture of Figure 8, participant 7 and participant 2, participant 5 and participant 1, participant 8 and participant 3. Direct tie is the most direct and firm form of inter-orbital cooperation, but it is also the least flexible inter-orbital cooperation. That's because the participants from different orbits and on the direct tie move at the same angular velocity. Participants in the same direct tie are in the same radial direction from the core. The direction of the giving force is consistent, and the direction of the getting force is also consistent. Moreover, the interaction between giving force and getting force can be directly carried out among the participants on adjacent orbits. Participants on layer $\boldsymbol{l} \boldsymbol{1}$ are better able to transfer core attraction forces and repulsive forces layer by layer to participants in other 
orbits that on the same direct tie. Therefore, participants forming direct tie can better interact with the core. But because the formation of direct tie requires the distribution that the participants must maintain the same radial direction. The participants on a same direct tie must move with a same angular velocity, which greatly limits the subjective initiative of participants. Therefore, direct tie is a minimum flexibility cooperation among orbits.

Forming direct tie is an effective way to achieve cooperation among different orbits. In addition, it is a common cooperation among orbits to help the participants on other orbits to block some participants. The blocked participants are those who the participants on other orbits do not want to join in their orbit by overtaking. In addition, there is a very common way of cooperation among orbits, that is, through the role of indirect force transmission to achieve cooperation among orbits. For example, participants 4 and 6 on the $\mathbf{l} 2$ orbit in the right diagram of Figure 8 do not form a direct tie with the $\mathbf{l} 1$ orbit, but can still interact with the real core by interacting with the inner equivalent core to support the operation of the inner orbit. The way of cooperation among orbits is called indirect tie. Indirect ties are the most basic and the most flexible way of cooperation among orbits. Participants 4 and 6, which form an indirect tie, are highly motivated and can change their moving angles.

In reality, the above three cooperative relationship among orbits is very common. If the participants on each orbit of the wheel model all form a direct tie, then the wheel model is called a fully stable cooperation model. In reality, the complete stable cooperation model is very rare. This competition and cooperation model is the most stable, but the flexibility of the model is also the worst. In reality, the specific form of wheel model used to guide or analyze competition and cooperation needs to be based on the actual situation. In the wheel model, there is only one competition relationship among the participants on the orbits, that is, striving to jump to a higher level orbit. There are mainly three kinds of cooperation between the participants on the orbits. Other more complex competition and cooperation relationships are based on these four relationships. In the actual situation, when the wheel model is used to analyze the relationship of competition and cooperation, it needs to be combined with the actual situation.

\section{Application of wheel model}

\section{Explanation of the operation of the state and the army}

In reality, competition and cooperation may not be fair to every participant. Some participants give more but get less. Some participants give less but get more. Competition and cooperation in reality is hard to make everyone equal. The Declaration of Independence 


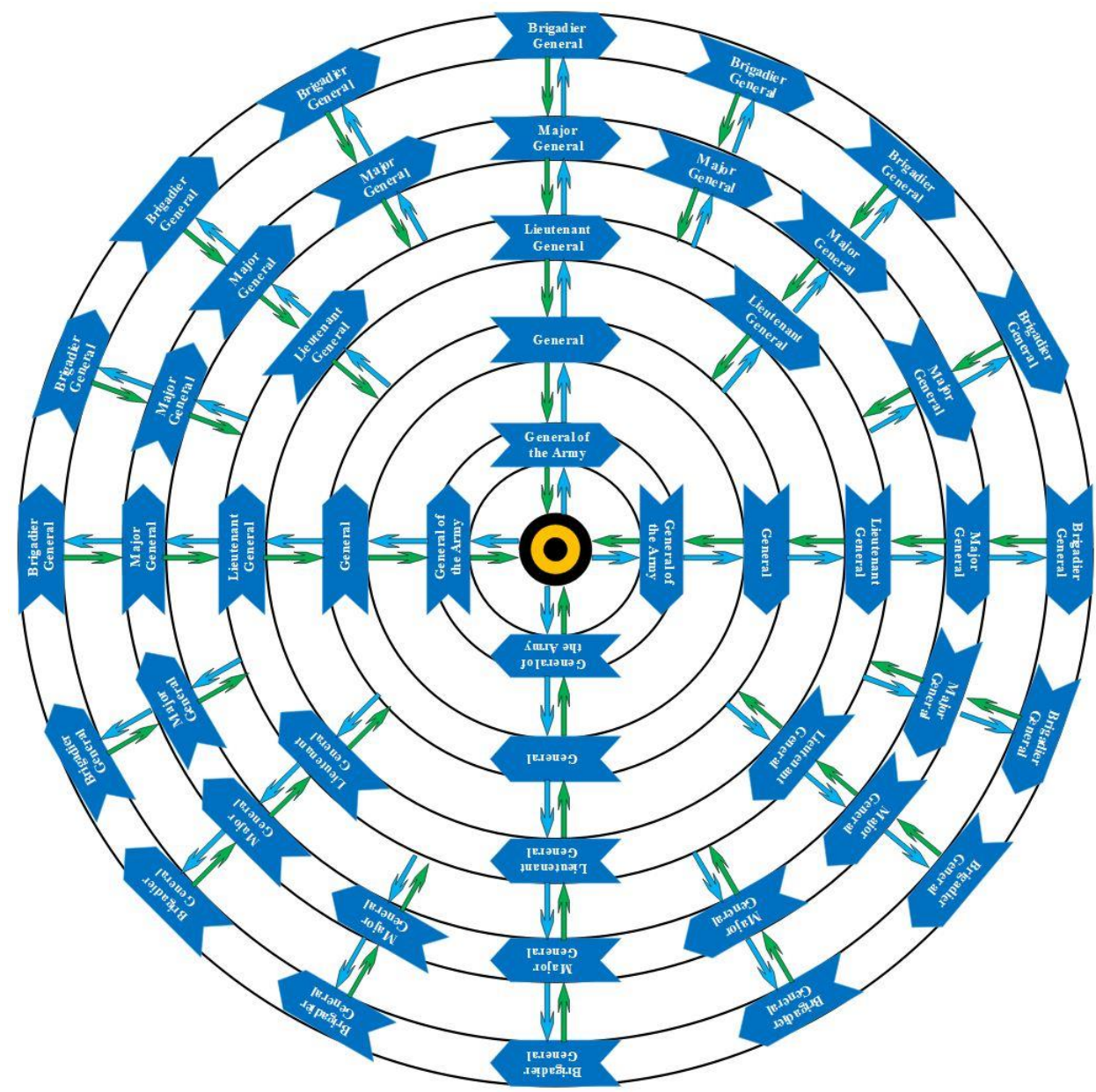

Figure 9. The application of the wheel model in the competition and cooperation relationship of United States army rank.

tells us that "all men are created equal." However, equality here, more refers to everyone has the same right to pursue a happy life and shoulder the social obligations that should be shouldered. It does not mean that everyone is born with the same ability to pursue a happy life and fulfill obligations to society. Reality is very realistic. In human history, competition and cooperation have never been absent. In view of history, we seldom have completely fair competition and cooperation. In some old social systems of feudal exploitation, it was difficult for the poor people in distress to have the ability to compete and cooperate with the exploiting ruling class. In the competition and cooperation system of the whole country or nation, if the wheel model is used to describe, then these poor people are in the outermost orbit of the wheel model, and the ruling class is often in the closest orbit to the core. Competition and cooperation exist within the same country, and competition and cooperation also exist between the state and the state. In the 20th century, the earth 
experienced two world wars, and the beautiful earth suffered from the torment and destruction of the war. Countless people lost their warm homes, lost their beautiful living, and even lost their precious life. War is a direct competition between life and death. During the world war, the fascist and the anti fascist allies were formed. Numerous competitions and cooperation have been carried out in different countries. The general situation of these competition and cooperation can be described by a wheel model. The Second World War took place in the last century, and historically, wars is constantly occurring on the planet on which we live. War is merciless and the most extreme way to deal with competition between countries or regions. Competition and cooperation between countries and regions should be built on the basis of no war. Because no country and people who live a good life really love war. As a weapon of a country or region, the discipline of the army must be strict and the level must be clear. Competition and cooperation in the army are equally strict. Napoleon said, "soldiers who do not want to be generals are not good soldiers". As a soldier, they should constantly enhance ourselves. But the army has strict discipline and various ranks. It is not easy to be a general. For example, in the modern U.S. Army, ranks are distinct from the highest to the lowest: General of the Army, General, Lieutenant General, Major General, Brigadier General, Colonel, Lieutenant Colonel, Major, Captain, First Lieutenant, Second Lieutenant, Chief Warrant Office, Warrant Office, Master Sergeant, Sergeant First Class, Sergeant, Corporal, Private First Class, Private, and Basic Private. The military rank system is complex. To give a simple example, we describe the relationship between competition and cooperation at the military rank system of the general with a wheel model.

As shown in Figure 9. Figure 9 shows only one case. The actual distribution of participants may be more complicated and no such rule in distribution. When using the wheel model, it is necessary to combine the actual situation.

\section{Explanation of company operation management}

In modern civilization, group cooperation is mainly distributed in the political and business circles. The political circle represents the political management and operation of the country or region, and the business circle represents the economic management and operation of the organization. For most people, it is more common to enter a company as an employee than to enter a national government agency as a government official. A company is an organization that aims at gaining profits. An efficient and reasonable company must exist competition and cooperation. As shown in Figure 10, it shows a wheel model of an IT company, which is composed of staff distribution. In this model of competition and cooperation, ordinary employees and engineers are on the lowest level of orbit. That is to say, participants on the same orbit do not necessarily belong to the same type. The 


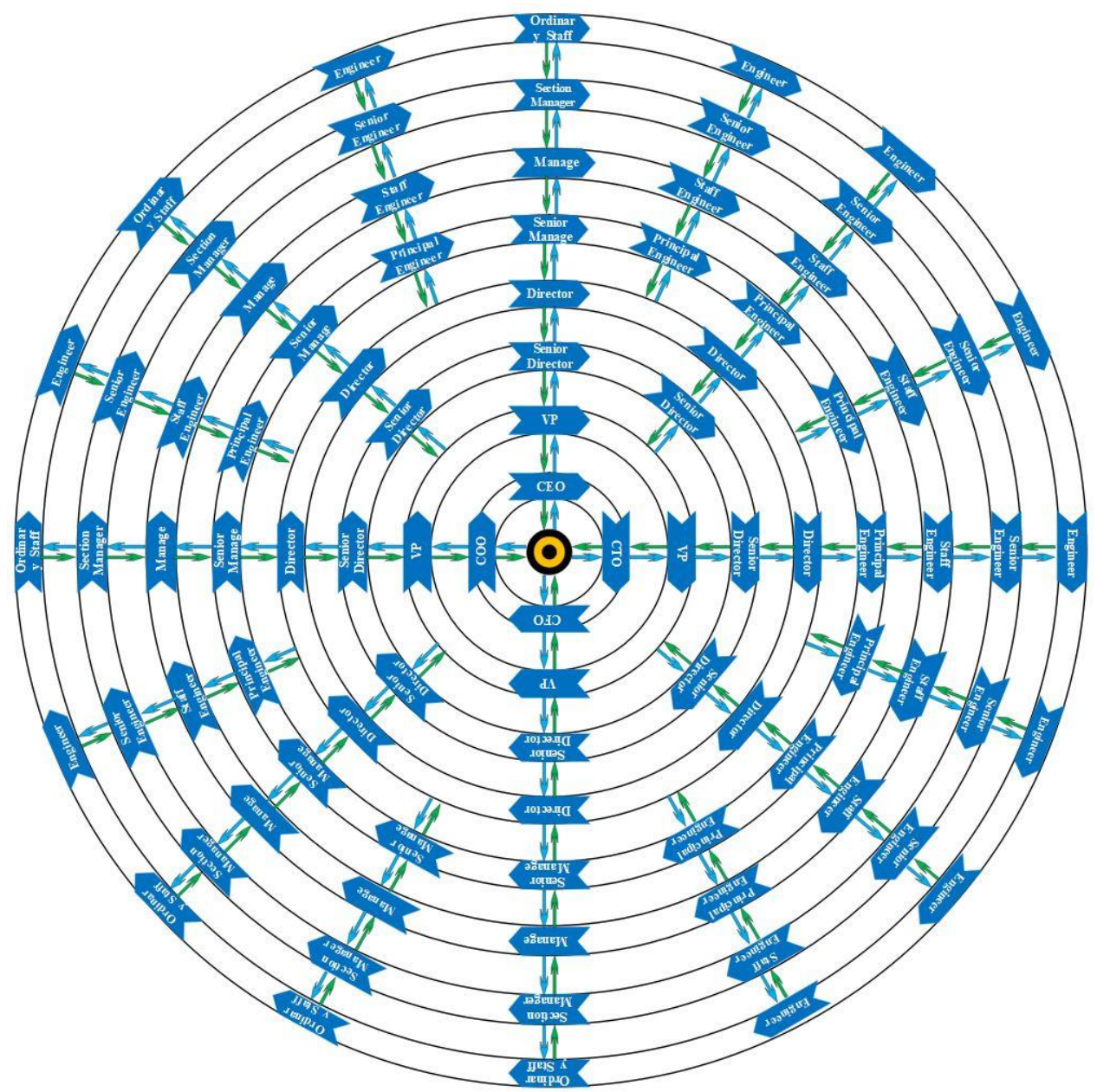

Figure 10. The application of wheel model in competition and cooperation of staff in a IT company.

participants on the highest level orbit of the wheel model are CEO, CTO, CFO and COO. Maintaining the driving force of the company is the core of the model. As the actual situation, the company's department management is a top-down direct tie management, therefore, the model uses many direct ties to the describe the relationship among the orbits. The competition among participants is to constantly jump to higher level orbits. In the model, most of the direct ties start from the core, but some of the direct ties start from a certain level orbit among the model. If a company's wheel model works well, then the company's operations will have good vitality.

Figure 10 shows only a wheel model of an IT company, which does not reflect all IT companies. The specific wheel model needs to be determined according to the actual situation. And the wheel model is dynamic, so the static wheel model diagram can only reflect a certain moment of competition and cooperation. However, this also reflects a 
feature of the wheel model, that is, dynamic variability, can reflect the current state of competition and cooperation in real time.

\section{Conclusions}

In order to vividly and concretely describe the relationship between competition and cooperation, we constructed a set of wheel model theory. The wheel model is dynamic, and the core of the model is to maintain the link between competition and cooperation. There are two ways to express the wheel model. The first one is similar to the expression of the circular motion of the wheel. The second one is a energy level transition expansion similar to the atomic level. The wheel model has at least one level orbit, at least two participants, and at least one participant on the same orbit. The spatial distribution of level orbits is not continuous. The level orbits of the wheel model is fixed. The participants on the orbit are moving. Participants on the same orbit are in the same level of energy. The level of energy corresponds to the scope of capability in reality. Each participant has a moving angle and a moving distance. The smaller the moving angle of the participants, the closer they are. Close participants may have competition, cooperation and indifference three kinds of actions. If the participants on the same orbit perform competition action, there will be an overtaking collision phenomenon. If the participants on the same orbit perform cooperation action, then there will be a partial hugging phenomenon. If the participants on the same orbit are indifferent to each other, then there will be no competition or cooperation phenomenon. In the wheel model, the faster the participants move, the greater the giving force they exert and the greater their energy will be, the more chances they will have to jump to higher-level orbits. The wheel model is an inductive model without strict mathematical derivation. But the law of the wheel model is from the rational philosophical point of view, is summed up from numerous examples and experiences of competition and cooperation. In order to explain more vividly the laws contained in the wheel model, we introduce the circular motion, collision and energy transfer in physics, as well as the laws of atomic energy level structure. Although the wheel model is an inductive model, it also has its own philosophy. Through the wheel model, any competition and cooperation relationship can be described. In this way, we can analyze the relationship between competition and cooperation in detail through the wheel model, philosophically and theoretically.

The ultimate idea that the wheel model wants to convey is that there are only two kinds of state relationships between the two parties or multiple participants in the face of the related necessary interests: one is competition, the other is cooperation. Competition and cooperation are two very wonderful and very common forms of natural philosophy. The 
world is pushing forward under these two important forces. In this world, circulation is a unique way. One of the most famous philosophers in Chinese history, Lao Tzu, once left a famous philosophical work to later generations, that is, the Tao Te Ching. Laozi's thought has a typical symbol map, that is, "yin yang fish". This picture is called "the first map of China". This picture shows the idea of "two poles". This is a kind of thought that exists at the same time of confrontation and cooperation. The relationship between competition and cooperation is similar to this kind of thinking. Competition and cooperation exist in the world at the same time, both of which together form a strong impetus to the evolution and development of civilization and nature.

The wheel model contains many philosophical ideas, and we need to explore and discover together. There may also be somewhere imperfect in the wheel model need us to work together to improve them. As a human being living in human society, competition and cooperation are unavoidable. Learning to handle competition and cooperation well is an important ability to live well in the world.

\section{ORCID iD}

Jinwe Lin (iD https://orcid.org/0000-0001-5562-1048

\section{References}

Aureli, F., Cords, M., \& Schaik, C. P. V. (2002). Conflict resolution following aggression in gregarious animals: a predictive framework. Animal Behaviour, 64(3), 325-343.

Barnosky, A. D., Matzke, N., Tomiya, S., Wogan, G. O., Swartz, B., \& Quental, T. B., et al. (2011). Has the earth's sixth mass extinction already arrived?. Nature, 471(7336), 51.

Bohr, N. (1914). Atomic models and x-ray spectra. Nature, 92(2310), 630-630.

Darwin, C. (2010). On the origin of species, 1859. New York University Press.

Guenther, D. B. (1989). Age of the sun. Astrophysical Journal, 339(2), 1156-1159.

Hallam, A., \& Wignall, P. B. (1999). Mass extinctions and their aftermath. Palaios, 14(4), 405.

Jr, J. E. W. (2011). Making the social world: the structure of human civilization (review). Journal of World History, 22(4), 811-816.

Madigan, P. (2011). Making the social world: the structure of human civilization. by john r. searle. Heythrop Journal, 52(1), 173-174.

Maienschein, J. (1982). A history of the study of human growth by j. m. tanner. Quarterly Review of Biology, 73(3).

Mayr, E. W. (1942). Systematics and origin of species. Evolution, 13(15), 7691-7697. 
Mitchell, J. S., \& Dill, L. M. (2005). Why is group size correlated with the size of the host sea anemone in the false clown anemonefish?. Canadian Journal of Zoology, 83(2), 372-376.

Murphy, G. P., \& Dudley, S. A. (2009). Kin recognition: competition and cooperation in impatiens (balsaminaceae). American Journal of Botany,96(11), 1990-1996.

Ni, X., Gebo, D. L., Dagosto, M., Meng, J., Tafforeau, P., \& Flynn, J. J., et al. (2013). The oldest known primate skeleton and early haplorhine evolution. Nature, 498(7452), 60-64.

Rosenzweig, M. L. (1995). Species diversity in space and time. Quarterly Review of Biology, 33(4).

Ruse, M. (1975). Charles darwin's theory of evolution: an analysis. Journal of the History of Biology, 8(2), 219-241.

Stinner, A. (2002). Calculating the age of the earth and the sun. Physics Education, 37(4), 296.

Trevors, J. T. (2006). The big bang, superstring theory and the origin of life on the earth. Theory in Biosciences, 124(3), 403-412.

van Zuilen, M. A., Lepland, A., \& Arrhenius, G. (2002). Reassessing the evidence for the earliest traces of life. Nature, 418(6898), 627-630.

United States Declaration of Independence. en.wikipedia.org. at:

https://en.wikipedia.org/wiki/United_States_Declaration_of_Independence (accessed 31 August 2018).

Whitfield, J. (2003). Bushmeat: the law of the jungle. Nature, 421(6918), 8-9.

Whittaker, R. H. (1972). Evolution and measurement of species diversity. Taxon, 21(2/3), 213-251.

Williams, C. (2005). Filling the ranks: transforming the us military system. Journal of

Politics , 67 (3), 944-946.

\section{Author biography}

Jinwei Lin is a very outstanding student in the Department of Electronics and Technology, School of Physics and Materials Science, East China Normal University, Shanghai, China. He is the original author of open source software PyDraw GUI drawing generator. A GUI Drawing Generator based on Tkinter (2018). His research areas include philosophy, methodology, computer, electronics, artificial intelligence, robotics, machinery, physics, chemistry, biology, mathematics and many other fields. $\mathrm{He}$ has master 10 kinds of computer programming languages. He has applied for more than 10 national patents. He has over 300 innovative designs and inventions. He has excellent innovative talents, active and intelligent thinking. 